\title{
Procedures for obtaining optimal SEM images of coccolithophore debris in coccolith limestones
}

\author{
Agnieszka Ciurej \\ Acta Palaeontologica Polonica 55 (1), 2010: 169-171 doi: http://dx.doi.org/10.4202/app.2009.0072
}

Coccolith debris in fossil zooplankton faecal pellets and the mode of its preservation are the unique source of data on the mode of feeding and digestion by ancient zooplankters. The animals are virtually absent in the fossil record in another form than their coprolites. However, minute structural details of coccospheres and their debris in the coccolith limestone are much less legible than in modern sediments. This paper presents how clear SEM images of details of coccolith plates in complete and dismembered coccospheres from fossil zooplankton faecal pellets can be obtained from thin sections of coccolith limestone. The images allow us to study the structural and compositional details of coccolith plates as well as their arrangements within the coccospheres and fossil faecal pellets.

Agnieszka Ciurej [agaciurej@yahoo.com], Faculty of Geology, Geophysics and Environmental Protection, AGH University of Science and Technology, Al. Mickiewicza 30, PL-30-059, Kraków, Poland.

This is an open-access article distributed under the terms of the Creative Commons Attribution License (for details please see creativecommons.org), which permits unrestricted use, distribution, and reproduction in any medium, provided the original author and source are credited.

\footnotetext{
Foris Full text (187.7 kB) ।

PaF 4 Supplementary file $(1,674.5 \mathrm{kB})$
} 